\title{
O Serviç̧ Social no Judiciário: construções e desafios com base na realidade paulista*
}

\author{
The Social Work in the Judiciary: constructions and \\ challenges based on the reality of São Paulo State
}

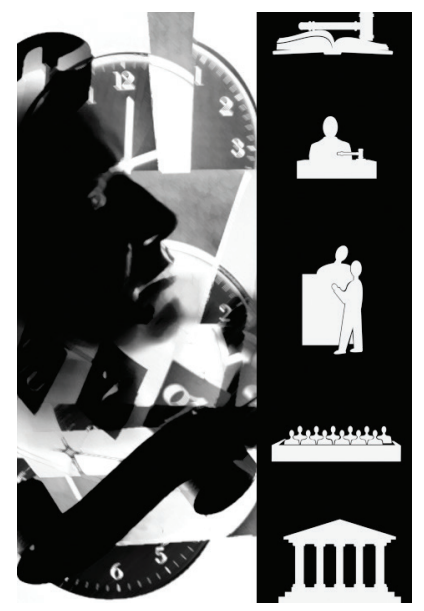

Eunice Teresinha Fávero**

Resumo: Este artigo apresenta algumas construções históricas e importantes desafios colocados ao Serviço Social no Judiciário. Para isso, toma como base o cotidiano profissional no Tribunal de Justiça do Estado de São Paulo, particularidades teórico-metodológicas e éticas que se fazem presentes no exercício profissional nessa área, e movimentos políticos da categoria em direção ao acesso e à garantia de direitos.

Palavras-chave: Serviço Social. Campo sociojurídico. Cotidiano profissional. Direitos.

\begin{abstract}
This article presents some historical constructions and important challenges for the Social Work in the Judiciary. For so, it is based on the professional daily activity in the Supreme Court of São Paulo State, on the theoretical-methodological particularities and ethical principles of the professional practice in this area, and on the category's political movements aiming at the access and the guarantee of rights.
\end{abstract}

Keywords: Social Work. Socio-juridical field. Professional daily activity. Rights.

* Este artigo tem como base palestras proferidas no V Encontro Estadual dos Assistentes Sociais e Psicólogos do Tribunal de Justiça do Estado de São Paulo, ocorrido em dezembro de 2012, promovido pela Associação dos Assistentes Sociais do Tribunal de Justiça do Estado de São Paulo (AASPTJ-SP), e no II Seminário Nacional sobre o Serviço Social no Campo Sociojurídico, em outubro de 2009, promovido pelo Conselho Federal de Serviço Social (CFESS).

** Assistente social/SP, com atuação e pesquisa na área judiciária; primeira secretária da AASPTJ-SP nas gestões 2001-2005 e 2009/2011; mestre e doutora em Serviço Social pela PUCSP; docente na Universidade Cruzeiro do Sul-SP, São Paulo, Brasil.E-mail: eunicetf@gmail.com. 


\section{Introdução}

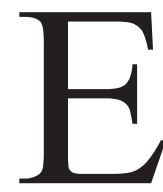

ste texto apresenta reflexões sobre as construções históricas e os desafios do Serviço Social no Judiciário, com base no cotidiano profissional do Tribunal de Justiça do Estado de São Paulo (TJSP). Reflexões e indagações a respeito do que tem sido construído e quais desafios estão postos no dia a dia de trabalho - tanto em termos de questões teóricas, metodológicas e éticas que permeiam o exercício profissional, como questões políticas presentes nesse fazer.

As ideias aqui expostas partem da experiência de trabalho no Judiciário paulista, da militância na Associação dos Assistentes Sociais e Psicólogos do Tribunal de Justiça do Estado de São Paulo (AASPTJ/SP), e de pesquisas sobre a história do Serviço Social nessa instituição, sobre condições de trabalho e sobre a realidade social constatada no trabalho cotidiano com indivíduos que vivenciam expressões da questão social, transformadas nesse espaço sócio-ocupacional em demandas judiciais - em especial nos âmbitos da Justiça da Infância e da Juventude e da Justiça da Família.

O debate sobre a história do Serviço Social no campo sociojurídico ${ }^{1}$ a partir do cotidiano profissional e, particularmente, as construções históricas dessa profissão no Judiciário paulista e seus desafios remetem à reflexão sobre a relação entre demandas com as quais os profissionais se deparam diariamente, a precarização do trabalho e a necessária organização coletiva para fazer frente às condições adversas do labor cotidiano. E isso com o propósito de fortalecer o potencial que o Serviço Social tem para contribuir com o acesso à Justiça e aos direitos humanos e, no seu interior, os direitos sociais.

1. Neste texto, "campo sociojurídico" é utilizado como sendo aquele que reúne "o conjunto de áreas em que a ação do Serviço Social articula-se a ações de natureza jurídica, como o sistema judiciário, o sistema penitenciário, o sistema de segurança, os sistemas de proteção e acolhimento como abrigos, internatos, conselhos de direitos, entre outros. O termo sociojurídico, enquanto síntese dessas áreas, tem sido disseminado no meio profissional do Serviço Social, em especial com a sua escolha como tema central da revista Serviço Social \& Sociedade n. 67 (Cortez Editora), pelo comitê que a organizou, tendo sido incorporado, a seguir, como uma das sessões temáticas do X CBAS — Congresso Brasileiro de Assistentes Sociais/2001" (Fávero, 2003, p. 10). Em trabalho que vem sendo realizado atualmente junto ao CFESS por Grupo de Trabalho constituído para elaborar as diretrizes de atuação dos assistentes sociais nesse campo, os conceitos de "campo" e de "área" estão sendo estudados (a partir de análises de Elizabete Borgianni), de maneira a ser definido o mais apropriado para nominar esse espaço sócio-ocupacional. 
Portanto, trata-se de um debate que leva em conta a história do Serviço Social no Judiciário, construída no cotidiano de trabalho pelos assistentes sociais e por todos os sujeitos com os quais eles interagem no exercício profissional, direta ou indiretamente. Então, história, cotidiano, trabalho, justiça e direitos se colocam como centrais nessa reflexão, com vistas a desvelar o exercício profissional lá na ponta, nas suas articulações com a realidade social e institucional.

Para caminhar até a história do tempo presente, quando os desafios estão postos concretamente, são retomados alguns marcos da história do Serviço Social no Brasil e no Judiciário paulista (com um flash sobre seu início e outro foco no presente), em articulação com a ética e as competências profissionais - sintonizadas (ou não) com fundamentos teóricos, metodológicos e técnicos do Serviço Social nos diferentes momentos. Nessa direção, vamos buscar também debater sobre como nessa história e nesse cotidiano o poder-saber profissional se põe frente às expressões da questão social.

\section{Marcos históricos: origem, prática profissional e ética}

O Serviço Social no Brasil tem 77 anos de existência, ${ }^{2}$ e o Serviço Social no Tribunal de Justiça do Estado de São Paulo tem 65 anos, ${ }^{3}$ ainda que desde o início da profissão neste país alguns assistentes sociais já realizassem trabalhos no então denominado Juizado de Menores, sem remuneração e/ou integrando o antigo Comissariado de Menores.

Os pioneiros do Serviço Social no TJSP foram também pioneiros do Serviço Social no Brasil, a exemplo da professora Helena Iracy Junqueira e do professor José Pinheiro Cortez. Ambos compuseram o grupo de professores da Escola de Serviço Social de São Paulo e militaram no Partido Democrata Cristão. Defendiam concepções de justiça social e de direitos com base no doutrinarismo católico, com um viés, ainda que embrionário, da social-democracia, e tiveram participação decisiva na implantação do Serviço Social no primeiro Juizado de Menores da capital,

2. Considerando como marco inicial da profissão no Brasil a criação da Escola de Serviço Social, em 1936, em São Paulo (SP).

3. Considerando como marco desse início a criação, em 1949, do Serviço de Colocação Familiar junto ao Juízo de Menores, na capital paulista. 
em 1949, por meio do Serviço de Colocação Familiar, ${ }^{4}$ instituído pela Lei estadual n. 500 - que ficou conhecida como Lei de Colocação Familiar.

Serviço este que, se utilizarmos denominação atual, pode ser considerado como o primeiro programa de família de apoio ou família acolhedora, ou, ainda, pode ser compreendido como o primeiro programa de transferência de renda de que se tem notícia no Estado de São Paulo, na medida em que incluía repasse financeiro inicialmente às famílias de apoio e posteriormente às próprias famílias das crianças e adolescentes cujos "casos" (como então se denominava) chegavam ao Judiciário com demanda de acolhimento institucional.

Em depoimento concedido em $1993,{ }^{5}$ o assistente social e professor José Pinheiro Cortez afirma, em relação ao auxílio financeiro à família de origem, previsto por esse programa para evitar a "internação de menores" (como se denominava então o acolhimento institucional de crianças e adolescentes), que:

A maior parte dos casos era de pobreza, que a gente tratando ou não tratando, continua pobre e que se eu não der comida não come. [...]. Era um dinheiro necessário para viver, mas não para tirar a condição de total dependência. Claro, a pessoa era estimulada a trabalhar [por meio do acompanhamento realizado pelo assistente social], mas dava-se o mínimo necessário, porque se não se desse isso, a criança ia para a rua ou para uma instituição e aí seria mais caro para o Estado e para a sociedade. (Fávero, 1999, p. 95)

Assim, respondendo às demandas colocadas pela ampliação das expressões da questão social, esse trabalho foi uma forma de assistência social com o objetivo de realização da justiça, vinculada ao ideário da doutrina social da Igreja Católica. O que, naquele momento histórico, não implicava questionamentos da ordem social burguesa que ditava a direção disciplinadora e controladora da ação profissional frente aos então chamados "desajustamentos sociais" (Idem, p. 95), que poderiam culminar no acolhimento institucional de uma criança ou adolescente.

4. A execução do Serviço de Colocação Familiar permaneceu sob a responsabilidade dos Juizados de Menores da capital até 1985, quando passou a ser administrado pelo Instituto de Assuntos da Família (Iafam), vinculado ao Poder Executivo estadual, vindo a ser extinto alguns anos depois.

5. Depoimento concedido para pesquisa de mestrado da autora deste texto. Tese publicada com o título Serviço Social, práticas judiciárias, poder: implantação e implementação do Serviço Social no Juizado de Menores de São Paulo, em 1999; e em 2005, com o título Serviço Social, práticas judiciárias, poder: implantação e implementação do Serviço Social no Juizado da Infância e Juventude de São Paulo, pela Veras Editora, São Paulo. 
O Serviço Social começa então, no Judiciário paulista, com uma direção mais voltada para a proposição e o desenvolvimento de ações que assegurassem alguma proteção social - ainda que com uma visão de justiça social direcionada pela doutrina social da Igreja Católica, que naquele momento iluminava a formação moral e ética dos estudantes de Serviço Social - e menos identificada com ações focadas no controle social de comportamentos considerados "desviantes" do padrão dominante burguês. Isso vai se dar com a criação e a formalização, em 1957, das Secções de Informações e de Serviço Social, que ficaram conhecidas como Serviço Social de Gabinete, trabalho que foi instituído em razão do aumento da demanda de natureza social e pelas competências inerentes aos profissionais dessa área, que detinham um saber específico sobre as relações sociais e familiares. Saber que passa a ser sistematizado em informes, relatórios ou laudos, com a finalidade de dar suporte à decisão judicial:

Então os relatórios eram assim: estudava-se profundamente o pedido, o significado do pedido, a situação familiar a respeito daquele problema que se apresentava ali digamos, orientando um pedido de internação: então vinha o significado da internação, a situação da família, o trabalho que se tinha feito com a família no sentido de evitar a internação, o entendimento feito com a escola para a criança frequentar escola. Também se acertava, por exemplo: todo mês a família tinha que vir trazer para o assistente social o boletim da criança ou a própria criança, ou havia um entendimento direto com a escola... O caso era bem conduzido, era bem apresentado, inclusive [...], quando você acabava de ler um relatório você tinha uma situação, um universo completo". (Depoimento Borges, apud Fávero, 1999, p. 117)

Então, isso significa que há aproximadamente sessenta anos os assistentes sociais têm como principais atribuições no Judiciário paulista: conhecer os sujeitos que procuram ou são encaminhados a essa instituição, em especial nas áreas da infância e juventude e família - sujeitos que, via de regra, vivem situações de violação de direitos e de conflitos os mais diversos; sistematizar esse conhecimento em informes, relatórios ou laudos, e encaminhar ao magistrado, de maneira a contribuir para que ele forme um "juízo" sobre a situação e defina a sentença, que poderá vir a ser definitiva na vida de indivíduos e famílias. Sentenças que desde aquela época e até os dias de hoje determinam o acolhimento institucional de crianças, as colocam em outras famílias, garantindo, em tese, sua proteção, aplicam medidas socioeducativas - da advertência à internação - , destituem o poder familiar, definem ou redefinem a guarda de filhos, dão base em alguns casos, ainda 
que indiretamente, à responsabilização penal de supostos violadores de direitos de crianças, mulheres, idosos etc.

Mas que subsídios são esses que cabia - e cabe - ao assistente social oferecer para contribuir com a decisão judicial? De que lugar profissional, institucional, político o assistente social falava e fala hoje? Por que o estudo social ou a chamada perícia social, com características muitas vezes descritivas do relato dos sujeitos atendidos e da demanda que apresentam, se tornou trabalho fundamental no Judiciário em detrimento de um maior investimento em diagnósticos sociais articulados com as amplas dimensões da realidade social e ações articuladas com outras organizações sociais e, dessa maneira, com maior possibilidade de contribuição para o acesso aos direitos e à justiça? E, afinal, de que Justiça se fala e que direitos são esses?

O assistente social foi e é chamado pelo Estado a fazer parte do Poder Judiciário para contribuir com a aplicação da lei. O estudo que realizava e que realiza, o parecer social que elabora com base nesse estudo, e que é registrado em um relatório ou laudo, tem contribuído para flexibilizar ou para manter inflexível a lei? A lei "tem um poder formal de gerir e de ordenar a vida, implicando em direitos e deveres". Na sociedade brasileira, em que a lei é essencialmente positivista, ela define, de acordo com Ewald (apud Fávero, 1999, p. 41), “um espaço de liberdade, traça-lhe os limites [...]; ela define uma partilha simples e imperfeita entre o permitido e o proibido; estabelece uma igualdade entre os cidadãos, que deixa na sua indistinção, pois é indiferente à sua existência singular". Dessa maneira, a lei generaliza e estabelece formalmente a igualdade entre os cidadãos, ainda que opere com desigualdades, as quais, nessa perspectiva, não são consideradas.

Assim, o estudo que o assistente social realizava e realiza contribui para desvendar a realidade em sua construção histórica e social, ou para ocultar - ou justificar - essa construção? Nesse sentido, na realização desse estudo sob uma perspectiva crítica, não se pode ignorar que a desigualdade e a exploração social que permeiam a realidade social são inerentes ao padrão capitalista que rege a economia e a política no Brasil.

Quando o Serviço Social tem início no Judiciário, o viés funcional positivista e o doutrinarismo social da Igreja Católica, aliados ao metodologismo do Serviço Social de casos individuais, de matriz norte-americana, eram referências para o exercício profissional. 
Esse início do Serviço Social no Judiciário paulista praticamente coincide com o estabelecimento do $1^{\circ}$ Código de Ética Profissional do Assistente Social, de 1948, fundamentado em pressupostos neotomistas e positivistas, em que

a ação profissional é claramente subordinada à intenção ético-moral dos seus agentes, entendida como uma decorrência natural da fé religiosa. A ética é concebida como a "ciência dos princípios e das normas que se devem seguir para fazer o bem e evitar o mal" (Abas, 1948, p. 40); ${ }^{6}$ sua importância é afirmada em face da atuação profissional voltada às "pessoas humanas desajustadas ou empenhadas no desenvolvimento da própria personalidade" (idem). (Barroco, 2001, p. 96)

A ética operava, portanto, de maneira prescritiva, traduzia na prática dogmas cristãos, e buscava o aperfeiçoamento da personalidade das pessoas atendidas, de maneira a que mantivessem "atitude habitual de acordo com as leis e os bons costumes da comunidade" (idem, p. 96, citando Abas, 1948).

As transformações sociais e culturais que ganham corpo particularmente no mundo ocidental, e sobretudo a partir da década de 1960, ainda que tenham envolvido significativos setores da sociedade brasileira, não aparecem de maneira explícita no Serviço Social naquele momento. Mesmo que tenham existido profissionais que se envolveram na luta por transformações e pela liberdade social e política, isso não vai refletir de forma clara nas normativas e na literatura da profissão, literatura que praticamente inexistia então, na medida em que o Serviço Social nesse período desenvolvia apenas uma dimensão interventiva e não investigativa, com bases científicas.

Todavia, considerando a consciência possível à época — entendida, conforme Goldmann, como o "máximo de possibilidade histórica que a consciência de um grupo possa ter em um determinado momento" (apud Baptista, 1986, p. 63) - e os limites teórico-metodológicos decorrentes do embasamento no neotomismo, no positivismo e no tecnicismo, nota-se uma preocupação com a autonomia profissional e os princípios éticos decorrentes dessa direção social da profissão, concorde-se ou não com eles nos dias de hoje. Isto é revelado em depoimentos concedidos pelo professor José Pinheiro Cortez e pela assistente social Zilnay Catão Borges, dois dos pioneiros do Serviço Social no Judiciário paulista.

6. Referência conforme texto original. 
O professor Cortez, ao analisar o papel do Serviço Social no Judiciário em suas primeiras décadas, ${ }^{7}$ afirma:

A ação do Serviço Social repousa muito mais na intencionalidade do próprio Serviço Social do que nos fatos sobre os quais ele atua [...]. Importante é definir o papel do Serviço Social na esfera do Judiciário. E esse papel não é uma definição só da lei nem só do Poder Judiciário. É também, e fundamentalmente, nossa, dos assistentes sociais. Então, vou trabalhar os Serviços Sociais junto ao Poder Judiciário a partir de uma ótica específica e nossa, e que eu vou tentar convencer o Poder Judiciário, o juiz, o legislador, seja quem for, a adotar essa ótica [...].

O problema da neutralidade do perito [...] existe, mas não deve existir; o indivíduo não é totalmente neutro na problemática social [...]. Essa postura que o assistente social condiciona o Serviço Social às instituições, inclusive à chamada Poder Judiciário, essa postura é que nós temos que questionar, não é correto. É um autossuicídio. É aceitar as instituições do momento, e o Poder Judiciário é um poder político, no sentido amplo da palavra político. (In: Fávero, 1999, p. 134-135)

Zilnay Catão Borges, por sua vez, ao falar sobre o poder inerente ao trabalho profissional no cotidiano, materializado em relatórios, ${ }^{8}$ afirma:

Nós tínhamos o direito, eu digo, de vida ou morte. Se você pegar os processos daquela época vai ver que eram relatórios grandes, até meio chatos para ler. Não chatos, porque eram muito bem-feitos, mas eram relatórios grandes, bons [...].

De jeito nenhum o assistente social alterava relatórios por exigência do juiz. Às vezes ele podia não concordar [...]. É um direito que lhe cabia, como juiz [...]. Ficava o nosso relatório, documentado, e o juiz colocava o parecer dele. Mas isso era raríssimo acontecer. [...]

[...] dava um medo danado. $\mathrm{O}$ medo era uma das discussões que a gente vivia tendo: gente, veja a responsabilidade que a gente está tendo, porque o juiz vê o que se escreve no final e põe "de acordo". Então, os casos não iam imediatamente para o juiz, eram muito bem estudados pela chefia e refeitos se algum aspecto não estivesse muito bem claro para justificar a medida final (idem, p. 116).

Ainda que outras marcas tenham sido importantes na história do Serviço Social no Judiciário paulista — como algumas experiências com trabalhos comu-

7. Depoimento em 1993 sobre o início do Serviço Social no Judiciário paulista.

8. Depoimento em 1994 sobre o início do Serviço Social no Judiciário paulista. 
nitários nos anos 1960 e 1970, bem como trabalhos interdisciplinares, realizados por profissionais significativos nessa história, e que fizeram diferença na ampliação e na qualificação do trabalho no Judiciário ${ }^{9}$ —, até por volta dos anos 1980 a marca da tradição positivista e doutrinária foi expressiva no exercício profissional do assistente social nessa instituição e, é possível afirmar, se faz presente em algumas intervenções até hoje, mesmo que a partir dos anos 1990 um novo projeto ético e político tenha passado a nortear a formação e a prática profissional do assistente social. Um projeto que é hegemônico, o que não necessariamente significa que seja de domínio e aceito por todos os profissionais na atualidade. Da mesma maneira que não é possível afirmar com segurança que antes dessa década, entre os profissionais que atuavam no Judiciário, não existissem vozes dissonantes do conservadorismo e do doutrinarismo social cristão, e que indistintamente todos assumiram integralmente uma perspectiva de trabalho apenas com vistas à adaptação dos indivíduos ao meio, que era característica do Serviço Social tradicional.

\section{Projeto profissional, trabalho no cotidiano e desafios contemporâneos}

A visita ao passado, em particular aos anos 1940-1950, com a perspectiva de conhecer um pouco da história e, como ensina o historiador italiano Alessandro Portelli (1997), "aprendermos um pouquinho com ela”, é importante para avanços na construção de transformações no presente e no futuro. Tais transformações dependem de os profissionais se indagarem e se posicionarem em relação às atividades que realizam no tempo presente e em que condições: em relação à ética profissional, às condições e relações de trabalho, à judicialização e à criminalização de expressões da questão social, às tentativas de uso desvirtuado do trabalho do assistente social para obtenção de provas testemunhais com vistas à responsabilização penal, e tantas outras questões e desafios com os quais os profissionais se deparam lá na ponta do exercício cotidiano de trabalho.

Torna-se importante a reflexão sobre como estão se posicionando e o que fazem os assistentes sociais no tempo presente no dia a dia de trabalho, nos diversos espaços que ocupam no Judiciário - alargando aqui o tempo presente desde o início da década de 1990 até os dias atuais. Como acontece a atuação na Justiça da

9. Como Terezinha Davidovich, João Batista Aducci, Maria Antonieta Guerriero e tantos outros. 
Infância e da Juventude, na Justiça da Família e nos demais espaços que demandam seu trabalho nessa instituição? Quais os referenciais teóricos e metodológicos que guiam a intervenção? Quais os princípios éticos que iluminam a escuta que estabelecem com os indivíduos, famílias e grupos com os quais trabalham, os relatórios que elaboram e os pareceres que emitem? Como estão sendo apropriadas as legislações sociais pós-Constituição Federal de 1988 e como se inserem e se articulam nesse trabalho as normativas e os programas sociais dela decorrentes? Como os profissionais se organizam politicamente para fazer avançar o compromisso com a efetivação da justiça social e dos direitos? E qual perspectiva de justiça social e de direitos norteia esse fazer profissional?

Não é pretensão nem é possível descrever aqui respostas a todas essas e a tantas outras questões que movem, ou que poderiam mover, os profissionais da área comprometidos com a direção social posta pelo projeto profissional hegemônico do Serviço Social na contemporaneidade. Mas são as perguntas à realidade que instigam a construção de novos caminhos em busca de respostas efetivas.

A década de 1990 marca essa história pela significativa ampliação do quadro de profissionais, tanto na capital (que já iniciara uma ampliação na década de 1980) como em cidades do interior do estado de São Paulo. Isso em virtude do constante aumento da demanda de trabalho, decorrente tanto da ampliação das expressões da questão social que chegam ao Judiciário devido à desigualdade social e à ausência ou insuficiência de políticas universais de proteção social, como das normativas legais e institucionais que estabelecem mais claramente a proteção de direitos de crianças, adolescentes, idosos, mulheres e famílias a partir da Constituição Federal de 1988.

Não é por acaso que essa década — nominada aqui de década de organização e de conquistas - marca a criação oficial da Equipe Técnica de Coordenação e Desenvolvimento Profissional dos Assistentes Sociais e Psicólogos do TJSP, para o planejamento e a execução das atividades de aprimoramento profissional. Marca também o início da organização política formal dos assistentes sociais e psicólogos do TJSP (que já vinham construindo um processo organizativo nos anos anteriores), com a criação, em 1992, da Associação dos Assistentes Sociais e Psicólogos do Tribunal de Justiça do Estado de São Paulo - AASPTJ-SP, com o objetivo de trabalhar, sobretudo, na direção da defesa de direitos desses profissionais. É também a partir da segunda metade dessa década que vários profissionais do Judiciário paulista - a maior parte deles com alguma participação na organização política da categoria - começam a desenvolver pesquisas no âmbito acadêmico sobre o traba- 
lho do assistente social no Judiciário e, portanto, a sistematizar conhecimentos com base científica sobre seu trabalho, articulando o fazer cotidiano a análises teóricas. ${ }^{10}$

Essa década de conquistas no âmbito do Judiciário paulista é a mesma em que o Serviço Social consolida as bases do atual projeto ético e político da profissão: em 1993, após amplo debate entre segmentos da categoria profissional, é estabelecido o atual Código de Ética profissional e promulgada a Lei n. 8.662/1993, que deu nova regulamentação à profissão, bem como, em 1996, são lançadas as atuais diretrizes curriculares pela Associação Brasileira de Ensino e Pesquisa em Serviço Social (Abepss). Documentos esses e diretrizes que marcam a ruptura do projeto profissional com a direção conservadora, assumindo claramente uma direção social no exercício profissional norteada pelos seguintes princípios:

\begin{abstract}
Reconhecimento da liberdade como valor ético central, pela defesa intransigente dos direitos humanos, pela ampliação e consolidação da cidadania, pela defesa do aprofundamento da democracia, o posicionamento em favor da equidade e justiça social, pelo empenho na eliminação de todas as formas de preconceito, pela garantia do pluralismo, pela opção por um projeto profissional vinculado ao processo de construção de uma nova ordem societária - sem dominação-exploração de classe, etnia e gênero, pela articulação com os movimentos de outras categorias, pelo compromisso com a qualidade dos serviços prestados e pelo exercício do Serviço Social sem ser discriminado nem discriminar. (CFESS, 2011)
\end{abstract}

Esses princípios éticos estão dispostos no atual Código de Ética Profissional e se contrapõem radicalmente àqueles estabelecidos no Código de Ética Profissional de 1948, que levavam a traduzir na prática dogmas doutrinários cristãos, ações na direção de ajustamentos de indivíduos à ordem social dominante, e valores moralizantes relacionados ao agir conforme "os bons costumes". Isto é, ao que a moral burguesa, ditada pelos detentores dos meios de produção e do poder político, definia que deveria ser o comportamento da população trabalhadora, a serviço dos interesses do capital.

10. Entre as profissionais/pesquisadoras estão Ana Maria da Silveira, Rita de Cássia Silva Oliveira, Abigail Franco, Selma Magalhães, Dalva Azevedo, Sílvia Alapanian, Dilza Silvestre Matias, Catarina Volic, Leni Ribeiro, Áurea Fuziwara, Ester Gast, além da autora deste texto. É importante destacar que a maioria dessas pesquisas foi acolhida e impulsionada pelo Núcleo de Estudos e Pesquisas sobre a Criança e o Adolescente da Pós-Graduação em Serviço Social da PUC-SP (NCA-PUC-SP), coordenado pela professora Myrian Veras Baptista. 
Mas não se pode esquecer que essa mesma década de 1990 foi marcada pelo avanço do neoliberalismo, da precarização do trabalho e pelo aumento considerável dos indicadores de pobreza, miséria e violência no Brasil. E isso, no que se refere à categoria dos assistentes sociais, vai se refletir mais explicitamente na década seguinte.

Assim, se a década de 1990 foi de consolidação da organização e de algumas conquistas, é possível afirmar que a primeira década do século XXI se torna a de resistência ao avanço desenfreado da precarização e da exploração do trabalho em geral, particularmente no que diz respeito ao Serviço Social, do trabalho do assistente social, e de lutas pelos direitos desses profissionais bem como pelo acesso e efetivação de direitos da população usuária dos serviços sociais.

Nesse contexto, no âmbito do Tribunal de Justiça do Estado de São Paulo, é extinta em 2001 a Equipe Técnica de Coordenação e Desenvolvimento Profissional dos Assistentes Sociais e Psicólogos do TJSP, praticamente eliminando as atividades de capacitação dos profissionais de Serviço Social e de Psicologia, sendo criados, enquanto espaço de resistência, apenas os Grupos de Estudos ${ }^{11}$ sobre diversos temas relacionados ao trabalho cotidiano, que passam a realizar reuniões mensais e são todos coordenados por assistentes sociais ou psicólogos do próprio TJSP, "sem ônus" para essa instituição. ${ }^{12}$

A pesquisa realizada pela AASPTJ/SP sobre as condições de trabalho dos assistentes sociais e psicólogos do TJSP, publicada com o título Serviço Social e Psicologia no Judiciário, construindo saberes, conquistando direitos (Fávero, Melão e Tolosa Jorge, 2005), revela claramente essa situação, demonstrada tanto pela bárbara realidade social da população atendida no dia a dia de trabalho do assistente social e do psicólogo (situações de extrema pobreza, violência interpessoal e intrafamiliar, não acesso à proteção social), como pelo sofrimento no trabalho vivido por muitos profissionais - pelas precárias condições materiais de tra-

11. Cabe aqui a lembrança de que entre as responsáveis pelo estabelecimento desses espaços de resistências estão as psicólogas Magda Melão e Denise Alonso, e a assistente social Sílvia Sant'Anna, e que por vários anos os encontros dos grupos aconteceram na sede da AASPTJ/SP, portanto, fora do espaço institucional.

12. Conforme ressalvado nas publicações das datas dessas reuniões (que continuam), no Diário Oficial da instituição. O que significa que os profissionais participantes são liberados do atendimento à população no dia da reunião, todavia devem dar conta de todo o trabalho pelo qual são responsáveis no dia a dia, bem como não recebem ajuda de custo para essa participação, e eventuais convidados para palestras não são remunerados pela instituição. 
balho, e ainda, em muitos casos, pelas relações verticalizadas e autoritárias por parte de superiores administrativos que ignoram e desrespeitam particularidades do trabalho do profissional.

Entretanto, no interior do permanente movimento da história, ao mesmo tempo também aparecem várias possibilidades e proposições de ações na direção da resistência, denotando o compromisso com a qualidade no trabalho, com base nas prerrogativas profissionais e nos direitos sociais.

Assim, nos primeiros anos da década de 2000 é que por fim os assistentes sociais conseguem que sejam definidas oficialmente suas atribuições profissionais (ainda que com cortes na proposta então encaminhada ao TJSP pela AASPTJ/SP). ${ }^{13}$ Também nessa década é que, por meio da AASPTJ-SP, a categoria organizada passa a estabelecer maior articulação com outras organizações sociais na busca da efetivação de direitos, sobretudo no que se refere aos direitos da criança e do adolescente. E que participa ativamente de movimentos de greve em conjunto com demais trabalhadores do Judiciário, e mais recentemente - na atual gestão da AASPTJ ${ }^{14}$ — inicia a caminhada em direção à maior articulação com profissionais de outros espaços sócio-ocupacionais do campo sociojurídico, visando ampliar e fortalecer a organização política das categorias, em direção ao acesso à justiça e aos direitos sociais.

Retomando as reflexões sobre a justiça e os direitos no cotidiano profissional, no tempo presente, é importante indagar sobre como o Serviço Social no espaço do Judiciário pode contribuir para o acesso à justiça e aos direitos em meio à barbárie que permeia a realidade social e que chega nesse espaço sócio-ocupacional fragmentada, geralmente como demandas individuais. Tudo isso necessita ser pensado tendo em perspectiva a apropriação das bandeiras da justiça e dos direitos enquanto meios estratégicos em direção à possibilidade histórica da justiça social que implique equidade, socialização da riqueza socialmente produzida, universalidade do acesso a bens e serviços que possibilitem e garantam a dignidade do ser humano (Fávero, 2012).

Os direitos humanos - de natureza social, econômica e cultural, em sua configuração moderna, como ensina Barroco (2009) — respaldam-se em conquis-

13. A íntegra das atribuições elencadas então pela AASPTJ-SP pode ser localizada anexa ao artigo "Questão social, família e juventude: desafios do trabalho do assistente social na área sociojurídica", de Marilda V. Iamamoto, publicado no livro Política social, família e juventude, 2004.

14. Gestão 2009-2013, que articulou ações com vistas à criação da Associação Nacional dos Assistentes Sociais e Psicólogos da Área Sociojurídica — AaSP Brasil — em 2012. 
tas não exclusivas da burguesia. Ainda que sejam limitados pela sua fundação com base na democracia e na cidadania burguesas, representando, portanto, interesses relacionados à defesa da propriedade privada e dos meios de produção inerentes ao sistema capitalista conforme cada país e momento histórico, a luta de classes possibilita que os trabalhadores incorporem a luta pelos direitos humanos como forma de resistência à exploração e à desigualdade, o que se concretiza em meados do século XX, com a agregação, nas declarações de direitos humanos, dos direitos sociais, econômicos e culturais aos direitos civis e políticos (Barroco, 2009, p. 57-58).

Assim, entende-se aqui que, mesmo nos limites da atuação cotidiana, uma das formas de materializar a contribuição com a justiça e os direitos nessa perspectiva pode se dar com o desvelamento e a interpretação crítica da demanda trazida e/ou vivida pelos indivíduos sociais (seja na abordagem individual ou coletiva) atendidos pelo assistente social.

No espaço de trabalho no Judiciário, o profissional encontra diversas situações de violações de direitos, expressas por pessoas que vivem muitas vezes em condições de apartação social, que passam por experiências de violência social e interpessoal, que estão por vezes em situações-limite de degradação humana, com vínculos sociais e familiares rompidos ou fragilizados, que vivenciam o sofrimento social decorrente dessas rupturas e da ausência de acesso a direitos. Nesse contexto, se o profissional trabalha em consonância com a defesa e a garantia de direitos, ele avançará nessa direção ao possibilitar um espaço de informação, de diálogo e de escuta desses sujeitos, ao estimular a reflexão crítica a respeito dos problemas e dilemas que vivenciam, ao agir, em conjunto com eles, para conhecer e estabelecer caminhos viáveis para o acesso a direitos.

Estabelecer o exercício profissional cotidiano com essa perspectiva exige o entendimento de que os processos de trabalho dos quais o assistente social participa têm como objeto as expressões da questão social e que essas expressões expõem violações de direitos, geralmente provocadas por situações estruturais e conjunturais - entendimento que pressupõe a análise crítica das dimensões que constituem esse processo de trabalho. Para isso, torna-se fundamental imprimir ao trabalho cotidiano a dimensão investigativa crítica, efetivando o processo de conhecimento da demanda que chega concretamente para o atendimento e a partir da qual a intervenção é desencadeada. E isso exige o domínio dos meios de trabalho, dos recursos materiais e, em especial, dos recursos teóricos, metodológicos, técnicos e éticos; 
exige processar o conhecimento da realidade social, seus movimentos, as correlações de forças e as suas possibilidades, tendo clareza da finalidade do trabalho. Ou seja, ter clareza do que é necessário conhecer, qual é a finalidade desse conhecimento, no interior das competências técnica, política e ética inerentes à área profissional, que revelam que profissão é essa e quem são os profissionais que a exercem.

Dessa maneira, ao realizar um estudo social por exemplo, que conteúdos pertinentes ao Serviço Social o assistente social domina, investiga e sistematiza? O que busca conhecer acerca de relações e de vínculos sociais presentes (ou ausentes) na vida dos sujeitos, no que se refere ao trabalho, com a cidade e com o território, com as políticas sociais? Como acontecem as relações com a família, qual sua capacidade protetiva, com qual proteção social o indivíduo e/ou a família conta? Como ensina a professora Aldaíza Sposati, vínculo em termos de proteção social é algo muito simples, é "contar com". O indivíduo ou a família conta com o quê? A resposta, conforme essa autora, é diferente para cada família, e por isso se faz necessário levar em conta sua condição objetiva. ${ }^{15}$

No exercício do trabalho cotidiano, a dimensão ética exclui qualquer possibilidade de desvirtuamento de sua finalidade, como, por exemplo, o uso de um laudo, de uma visita domiciliar ou de uma entrevista no espaço físico da instituição com o objetivo de obter informações que venham a servir de provas para aplicação de punição a um suposto violador de direitos de uma criança ou suposto autor de outros crimes. O conteúdo expresso em um relatório ou laudo pode nessa área judiciária ser considerado como mais uma "prova" em ações de responsabilização penal, mas o objetivo, quando da sua construção, não é esse. O trabalho realizado pelo assistente social ao comportar a dimensão investigativa tem como inerente a produção do conhecimento sobre o cotidiano e seus sujeitos, de modo a explicar a realidade social e contribuir com a efetivação de direitos, e não a construção de provas que sirvam de base a ações de responsabilização na área criminal.

Nesse sentido, um dos desafios postos aos assistentes sociais que atuam no Judiciário (mas não só nessa área) está em não fazer uso do saber-poder, que é inerente ao exercício profissional, em contraposição à ética profissional. O que, no espaço do Judiciário, pode acontecer de maneira mais diluída, na medida em que o poder decisório é inerente à "natureza" institucional. Nos processos de trabalho,

15. Anotações de conferência sobre "Vulnerabilidade e capacidade protetiva de territórios e famílias", realizada por Aldaíza Sposati em aula magna no mestrado em Políticas Sociais da Universidade Cruzeiro do Sul/SP, em 10 de maio de 2012. 
ao realizar entrevistas e registrá-las em relatórios, o assistente social sistematiza um saber a respeito dos indivíduos e grupos atendidos que, no âmbito do Judiciário, pode ser tomado como "verdade" e interpretado em diferentes perspectivas. Esse conhecimento produzido, para revelar-se como ponto de vista do Serviço Social, necessita ter como base fundamentos teóricos, metodológicos e éticos inerentes à profissão, e ser expresso com clareza, concisão e consistência. Entretanto, ao ler um laudo ou um relatório, qual é o ângulo de visão de um promotor, de um juiz, de um gestor? Que leitura e interpretação podem fazer? Que direção social e profissional guiará a decisão em relação à medida a ser tomada?

O relatório social, o laudo social e o parecer social podem ser vistos como instrumentos de poder. Um poder-saber que necessita ser viabilizado na direção da garantia de direitos, em estreita articulação com o atual projeto profissional do Serviço Social, e não como indicador de ações disciplinares, coercitivas e punitivas, desvirtuando a finalidade do trabalho que cabe ao profissional da área. Para isso, é essencial a investigação rigorosa da realidade social vivida pelos sujeitos e grupos sociais envolvidos nas ações judiciais, desvelando a dimensão histórico-social que constrói as situações concretas atendidas no trabalho cotidiano.

Nessa linha de construções e de desafios, considera-se necessário o investimento na área de trabalho judiciária como espaço de investigação permanente, de maneira que suas produções contribuam com a criação de resistências à desvalorização do saber profissional, à criminalização da pobreza e à judicialização dos conflitos familiares e das expressões da questão social. Assumir efetivamente a pesquisa também como instrumento de trabalho, contribuindo para que o conhecimento dela decorrente seja aplicado no dia a dia da intervenção e contribua com avaliações e proposições de políticas sociais e institucionais, coloca-se como importante desafio.

Para lidar com desafios e realizar investimentos em algumas frentes, no sentido de contribuir com o acesso à justiça e aos direitos, ao fortalecimento da capacidade argumentativa e consequente fortalecimento do projeto da profissão na contemporaneidade, é necessário o estabelecimento de estratégias e a efetivação de ações políticas organizadas.

Avanços nesse sentido possivelmente poderão ser alcançados se ações coletivas forem viabilizadas. Entre tais ações considera-se importante: construir parâmetros que definam um número mínimo de profissionais em relação ao número de processos e situações atendidas em cada Vara e/ou Fórum - em articulação com outras áreas do conhecimento e organizações políticas; manter a vigilância e articulações para que o acesso a essa área de trabalho seja por meio de concursos públicos, para 
os quais as organizações representativas da categoria devem ser chamadas a opinar em termos de projeto de profissão e, inerente a isso, por exemplo, sobre a bibliografia-base para esses concursos; organizar, nacionalmente, mobilização para que o assistente social (e demais profissionais que compõem as equipes multiprofissionais) não seja subordinado administrativamente ao magistrado titular da Vara onde atua. Nesse sentido, considera-se importante a elaboração de proposta para que as equipes técnicas que atuam no Judiciário tenham coordenação própria, indicada pela categoria organizada, prestando serviços no âmbito do sistema de justiça à população que dele necessita, sem que os profissionais precisem, a cada dia, provar a que vieram para cada superior hierárquico que chega a uma Vara de Família, Vara da Infância, Vara Criminal, ou em outros espaços de trabalho da área - superiores muitas vezes alienados da dimensão histórica e política da realidade social e do trabalho que compete aos profissionais de Serviço Social.

Entende-se como necessário o estabelecimento de estratégias para conquista de autonomia administrativa porque, sem desconsiderar a existência de magistrados ou gestores comprometidos com o respeito ao direito da população e aos direitos dos trabalhadores na instituição, permanece ainda de maneira expressiva no Judiciário, particularmente no paulista, situações de autoritarismo, reforçadas pela posição hierárquica administrativa, que não raro invade a autonomia técnica, sobretudo no âmbito da Justiça da Infância e da Juventude. E essa realidade muitas vezes tem como consequência o adoecimento dos profissionais, a alienação, quando não a saída da instituição em busca de outro trabalho, ou a constante contagem dos dias que faltam para a aposentadoria. E, é importante lembrar, tudo isso não nos exime de considerar que como em todas as áreas, também podem existir profissionais do Serviço Social coniventes com o autoritarismo, com a banalização da vida humana e com o desrespeito à ética.

É fundamental a valorização do trabalho interdisciplinar — porém mantendo relações de horizontalidade, e não de subalternidade —, do próprio conhecimento e de ações nele embasadas.

Estreitamente articulado a esse desafio e proposição, é importante organizar o debate e encaminhamentos para a criação, na estrutura administrativa do Tribunal de Justiça, de Secretaria de Serviço Social e de Psicologia (e/ou outras áreas do conhecimento que integram ou venham a integrar a equipe multiprofissional), vinculada diretamente à presidência do Tribunal, dirigida de direito e de fato por esses profissionais. Uma secretaria com autonomia, poder decisório e dotação orçamentária para desenvolvimento, entre outros, de projetos de formação continuada dos profissionais 
e de assessoria a eles nas variadas particularidades do exercício profissional cotidiano, o que poderia ser viabilizado por meio de atividades de supervisão continuada.

Entre as estratégias necessárias para fazer frente aos desafios, coloca-se a ampliação da organização política ${ }^{16} \mathrm{e}$, vale reafirmar, o investimento na pesquisa, na produção de conhecimentos com base nas demandas e nas atividades de trabalho que os assistentes sociais realizam cotidianamente. Conforme já observado, é imprescindível a inserção dessa dimensão investigativa no trabalho cotidiano, ou seja, inserir a pesquisa como parte dos processos de trabalho, socializar os seus resultados, de maneira a contribuir com avanços qualitativos no exercício profissional e como suporte à luta política. Nesse sentido, é importante provocar a universidade para que viabilize pesquisas e estudos críticos sobre essa área, ainda um tanto distante do debate acadêmico.

Uma estratégia que também poderá fortalecer essa área de trabalho está na definição das competências e de parâmetros para a atuação dos assistentes sociais no campo sociojurídico, que vem sendo desenvolvida pelo conjunto CFESS/Cress. E que necessita avançar na busca da participação da categoria que está lá na ponta do atendimento, para que se manifeste sobre o que faz e o que propõe, com base na diversidade de experiências e realidades socioterritoriais do país.

São muitas as construções e maiores ainda os desafios postos aos assistentes sociais como um todo, particularmente os do Judiciário, conforme tratado neste texto. Não foi pretensão pontuar todos esses desafios, nem será possível avançar na construção de respostas num curto prazo. São construções e desafios que não se dão isoladamente no espaço local de trabalho, apartados da conjuntura social e política nacional e mundial e sem articulações com outras organizações sociais e políticas. São os desafios postos no cotidiano que movem a história, e esse movimento necessita ser desvelado e influenciado pelos profissionais, tanto no dia a dia da luta política como no dia a dia da intervenção profissional - com democracia, sem preconceitos, respeitando a diversidade e as diferenças, e com compromisso com a qualidade dos serviços prestados, como tão claramente alerta o Código de Ética Profissional do assistente social.

Recebido em 31/5/2013 - Aprovado em 10/6/2013

16. O que, no estado de São Paulo, a AASPTJ/SP tem buscado levar à frente, com a luta pela ampliação de seus quadros e áreas de abrangência. 


\section{Referências bibliográficas}

BAPTISTA, M. V. Goldmann e o estruturalismo genético. Serviço Social \& Sociedade, São Paulo, n. 21, 1986.

BARROCO, M. L. S. Ética e Serviço Social: fundamentos ontológicos. São Paulo: Cortez, 2001 .

A historicidade dos direitos humanos. In: FORTI, V.; GUERRA, Y. (Orgs.). Ética e direitos: ensaios críticos. Rio de Janeiro: Lúmen Júris, 2009. p. 55-62.

CFESS. Código de Ética do/a Assistente Social. Resolução CFESS n. 273/1993. In:

Legislação e resoluções sobre o trabalho do assistente social. Brasília: CFESS, 2011.

LEI n. 8.662/93. Dispõe sobre a profissão de Assistente Social e dá outras providências. In: Legislação e resoluções sobre o trabalho do assistente social. Brasília: CFESS, 2011.

FÁVERO, E. T. Serviço Social, práticas judiciárias, poder: implantação e implementação do Serviço Social no Juizado de Menores de São Paulo. São Paulo: Veras, 1999.

Estudo social: fundamentos e particularidades de sua construção na área judiciária. In: CFESS (Org.). O estudo social em perícias, laudos e pareceres técnicos: contribuição ao debate no Judiciário, no penitenciário e na Previdência Social. São Paulo: Cortez, 2003.

. Serviço Social, práticas judiciárias, poder: implantação e implementação do Serviço Social no Juizado da Infância e Juventude de São Paulo. São Paulo: Veras, 2005.

. O estudo social na perspectiva dos direitos. In: XX Seminario Latinoamericano de Escuelas de Trabajo Social. Córdoba, Argentina, 2012. CD-ROM.

MELÃO, M.; TOLOSA JORGE, M. R. (Orgs.). Serviço Social e Psicologia no Judiciário: construindo saberes, conquistando direitos. São Paulo: Cortez, 2005.

IAMAMOTO, M. V. Questão social, família e juventude: desafios do trabalho do assistente social na área sociojurídica. In: SALES, M. A.; MATOS, M. C.; LEAL, M. C. (Orgs.). Política social, família e juventude. São Paulo: Cortez, 2004.

LEAL, Maria Cristina; MATOS, Maurilio Castro; SALES, Mione Apolinário. Política social e juventude: uma questão de direitos. São Paulo: Cortez, 2004.

PORTELLI, A. Tentando aprender um pouquinho: algumas reflexões sobre a ética na história oral. Projeto História. Revista do programa de pós-graduados em História e do Departamento de História — PUC-SP. São Paulo, n. 15, 1997. 